\title{
The Activity of d-Limonene from Sweet Orange Peel (Citrus sinensis L.) Exctract as a Natural Insecticide Controller of Bedbugs (Cimex cimicidae)
}

\author{
SRI MURSITI ${ }^{1 *}$, NANDA AYU LESTARI ${ }^{2}$, ZERLINDA FEBRIANA ${ }^{3}$, \\ YUAN MAYLIA ROSANTI ${ }^{4}$ and TRI WAHYU NINGSIH ${ }^{5}$
1,2,3,4 Chemistry Department, Faculty of Mathematics and Natural Sciences, Universitas Negeri Semarang, Indonesia.
${ }^{5}$ Biology Department, Faculty of Mathematics and Natural Sciences, Universitas Negeri Semarang, Indonesia.
${ }^{*}$ Corresponding auhtor E-mail: kumalasari_berliana@yahoo.com

Doi http://dx.doi.org/10.13005/ojc/350424

(Received: November 13, 2018; Accepted: July 05, 2019)

\begin{abstract}
Bedbugs are harmful human blood-sucking ectoparasites. The disadvantages of a bedbug bite cause itching, redness bumps, secondary infections, and anemia in children. Bedbugs controller so far uses harmful chemical pesticides, but reappearance of bedbugs indicates less effective chemical pesticides, and becomes a serious problem. So it needs safer controller for human health. This study aims to analyze the d-Limonene activity of orange peel (Citrus sinensis $L$.) in controlling the bedbug infestation (Cimex cimicidae). The study was conducted through 5 stages: d-Limonene isolation, GC-MS characterization, bioassay $Y$ test d-Limonene nanoparticles, SEM characterization, and d-Limonene activity test on bedbug. The results showed that the essential oil of orange peel contained the main compounds as d-Limonene (90.018\%), 1,6-Octadien-3-ol, 3,7-dimethyl- (3,017\%), $\beta$-Myrcene (2.071\%), Octanal $(0.349 \%)$, 1-Octanol (0.589\%), 1R- $\alpha$-Pinene (0.688\%), 6-Octen-1-ol, 3,7-dimethyl- $(0.667 \%)$, 3-Cyclohexene-1- methanol, $\alpha, \alpha$, 4-trimethyl-, (S)-(1.453\%), and Bicyclo [3.1.1] heptane, 6.6-dimethyl2-methylene-, (1S) - (1.147\%). The Bioassay $Y$ test shows that d-Limonene was both repellent and fumigant, d-Limonene nanoparticles had uneven and irregular surface morphology, and in the flea activity test showed more than $50 \%$ bedbugs death. These research concluded that d-Limonene compounds from sweet orange peel had activity to control the bedbugs.
\end{abstract}

Keywords: Citrus sinensis L, Cimex cimicidae, d-Limonene, Natural Insecticide.

\section{INTRODUCTION}

Bedbug (Cimex cimicidae) is a human bloodsucking extoparasite found in subtropical and tropical countries. The problem of bedbugs found in many homes, theaters, and hotels in the late 1970s. The bedbugs were controlled using insecticides, so there was almost no information about the bedbug attacks in 1980-2000. Reemergence of bedbug infestation in the last five years in several star hotels, inns, dormitories,

This is an Open Access article licensed under a Creative Commons license: Attribution 4.0 International (CC- BY). Published by Oriental Scientific Publishing Company @ 2018

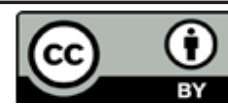


and residential houses. ${ }^{1}$ This appearance was due to the lack of effective chemical insecticides.

Bedbugs live in groups and easily to be founded in dormitories, hospitals, and hotels. Preferred residences are bed bugs in crevices, cracks, furniture (chairs and beds), rear wallpaper, bedding, wood panels, or under carpets. Bedbugs are active at night (nocturnal), but when hungry during the day bedbugs can also appear and approach to the host. ${ }^{2}$

Infestation of bedbugs had a negative impact on health and the economy. ${ }^{3}$ The bitting bedbugs can cause itching, reddish bumps, secondary infections caused by repeated cardiac itching, and result in anemia in children at high infestation. This is very harmful to humans. The flea controller used by people today was chemically controlled because it was considered practical and powerful to kill bedbugs.

The d-Limonene, an active ingredients present in the essential oil destroy the wax layer of the insect respiratory system so that once applied directly, the insects will suffocate. ${ }^{4} \mathrm{~d}$-Limonene bioassay results of tests undertaken after treatment of the fabrics, Bioassay results show the toxic activity of MCT-b-CD finished cotton fabrics treated with different doses of limonene, and also show the effect of exposure time against mosquitoes. The results show that the repellent, knockdown and killing action against mosquitoes increased with increasing concentration of limonene in MCT-b-CD finished cotton fabrics within the range studied (250-1500 $\mathrm{mg} / \mathrm{m}^{2}$ ). Also, results show that the corrected activity (repellency, knockdown and mortality) increased by increasing the exposure time. ${ }^{5}$

Existing research results showed that total of 24 compounds were identified and the major components were d-Limonene $(86.75 \%)$, linalool $(1.96 \%), \alpha$-pinene $(1.63 \%)$, trance-limonene oxide (1.39\%), and $\gamma$-terpinene (1.03\%). ${ }^{6}$ Extensive studies on the chemical composition of various $C$. sinensis species have also been conducted. $d$-Limonene is the most abundant component in citrus peels volatile extract and constitutes $51.97 \%-95.35 \%$ of the total amount. ${ }^{7}$

Extensive studies on the chemical composition of various species of Citrus Sinensis
L. had been performed. The antimicrobial activity of sweet oranges (Citrus Sinensis L.) had not been fully investigated, and little was known about its activity against fungi that produced toxins, such as Aspergillus flavus and Aspergillus parasiticus. ${ }^{6}$

d-Limonene is used as insecticide to control ectoparasites of pet animals, but it has activity against many insects, mites, and microorganisms. Possible attractive effects of limonene to natural enemies of pests may offer novel applications to use natural compounds for manipulation of beneficial animals in organic agriculture. ${ }^{8}$

The potential of volatile oil against insects was resistant (repellent), fumigant (fumigant), reduce appetite (antifeedant), and attract (attractant). ${ }^{9}$ The advantage of $d$-Limonene over synthetic pesticides in this regard is its biodegradability, which makes it more environmentally friendly for both fumigation and contact applications. The broad range of pharmacological properties of d-limonene coupled with low toxicity offers the possibility of incorporating this compound into various medical and cosmetic formulations. ${ }^{10}$ Natural plant products and materials have been used by local people as insecticides to control insects such as mosquito. Among the most notable plants having such insecticidal properties are Azadirachta indica (neem) and Citrus sinensis (sweet orange). ${ }^{11}$

Research had been carried out on citrus plants isolated to produce essential oils from orange peel (Citrus nobilis L.), was carried out using the steam distillation method. ${ }^{12}$ has conducted a study to test the activity of biothermal activity in the leaves of citrus Nobilis lour against termites (Coptotermes curvignathus sp) showing a concentration of $20 \%$ volatile oil with $100 \%$ mortality toxic.

This research about activity of d-Limonene from sweet orange peel as a natural insecticide controller of bedbugs and there was no conflict of interest in this study.

\section{MATERIALS AND METHODS}

\section{Instruments, Tools and Materials}

These research used GC-MS instruments, glasses tool set such erlenmeyer, beaker, flakon bottle, analytical balance, $\mathrm{Y}$ tube, microliter syringe, 
stopwatch, magnetic strirrer, scanning electron microscope (SEM), glass spray diameter $1.8 \mathrm{~cm}$ and height $3 \mathrm{~cm}$, tally counter, desiccator, separating funnel, and oven. The materials were include the cemetery colony (Cimex cimicidae), hexane, glacial acetic acid, Whatmann $\mathrm{N}^{\circ} 1$ (15 cm diameter) disc, Whatman paper No. 41 , sterile sand, plaster paris, regent, black cloth, strimin woof, and $\mathrm{Na}_{2} \mathrm{SO}_{4}$.

\section{Preparation of Bedbugs and d-Limonene Compounds}

Bedbugs (Cimex cimicidae) obtained from boarding houses around the State University of Semarang. Sampling of the extract of d-Limonene was carried out by using a simple distillation apparatus for 8 $\mathrm{h}$ to obtain sweet orange peel oil. The sweet orange peel oil was separated from the water using a separating funnel then separated back using $\mathrm{Na}_{2} \mathrm{SO}_{4}$. The extract be used directly or stored at room temperature until the next analysis process (Bioassay $\mathrm{Y}$ ).

\section{Bioassay Y Compound d-Limonene}

Bioassay was done under standard conditions with $90 \%$ relative humidity and room temperature of $28^{\circ} \mathrm{C}$. The two extracts produced (d-Limonene) were tested using bioassay $Y$ on Whatmann $\mathrm{N}^{\circ} 41$ disc paper, with an intermediate angle of $120^{\circ}$. In $Y(3 \mathrm{~cm})$ and one $Y(7 \mathrm{~cm})$ branch, artificial trail was drawn using a microliter syringe in which there was $1 \mathrm{~mL}$ of extract per $1 \mathrm{~cm}$ marker. Other extracts or pure solvents (hexane) as controls, were placed in the same conditions on the basis of $Y$ and other $Y$ branches. Then a bedbug was placed in a $55 \mathrm{~mm}$ diameter small bottle at the bottom of $\mathrm{Y}$, and the distance of bedbugs was measured. The time spent between introducing bedbugs to bottles and bottle relics by bedbugs was also measured to determine the role of the marker in determining the behavior of bedbugs.

The d-Limonene compound was tested 3 replicates $(n=3)$ and each repeated using a new bed bug and filter paper to prevent the effect of precondition conditioning behavior. The activity threshold for both synthetic extract and d-Limonene was determined as the minimum concentration inducing bedbugs to cover an average distance of more than $3 \mathrm{~cm}$. While the maximum response was $10 \mathrm{~cm}$.

Preparation of Nanoparticles d-Limonene with Chitosan

Chitosan of $1 \mathrm{~g}$ dissolved in $100 \mathrm{~mL}$ glacial
$1 \%$ acetic acid using magnetic stirer to obtain $1 \%$ chitosan parent solution. Take $80 \mathrm{~mL}$ of $1 \%$ chitosan solution and added bitwise to $100 \mathrm{~mL}$ d-Limonene over magnetic stirer. Stirring was continued for $30 \mathrm{~min}$ to obtain a stable solution of d-Limonene nanoparticles. The nanoparticles were looked at their size and morphology under an electron scanning microscope (SEM).

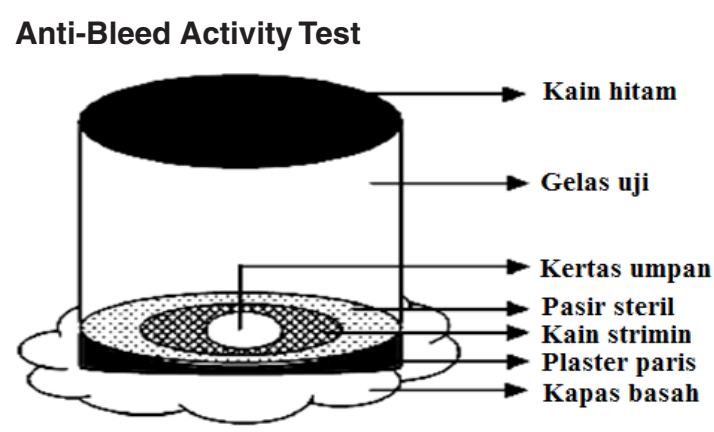

Fig. 1. Anti-Bleed Activity Test

Anti-flea activity of sweet orange peel extract in the form of $d$-Limonene compound was tested using force feeding test which has been done by some modifications. Test glass made of plastic material (diameter $5 \mathrm{~cm}$, height $5 \mathrm{~cm}$ ). The bottom of the test glass was a porous plaster of paris and contained sterile sand $10 \mathrm{~g}$ weight.

The feed paper (diameter $2 \mathrm{~cm}$; Whatman paper No. 41) was stirred at $60^{\circ} \mathrm{C}$ for $1 \mathrm{~h}$ stored in desiccators for $24 \mathrm{~h}$ then weighed for initial weight. The feed paper was immersed in a solution of d-Limonene nanoparticles for $1 \mathrm{~h}$ with $0 \%$ concentration (negative control), $4 \%$, and $8 \%(\mathrm{w} / \mathrm{v})$. Negative controls no treatment of addition of extract (solvent only).

After immersion, the feed paper was dried to evaporate the solvent. The $4 \mathrm{~cm}(4 \mathrm{~cm})$ diameter strimine cloth (modified) was placed in a test glass and on a strimin cloth is placed in the feed paper. Test glass was placed in a container with the bottom of which was given wet cotton. A total of 35 active bedbugs were inserted into the test glass. The test glass was covered with a black cloth and kept in a place protected from light for 3 days. The feed paper was stirred at $60^{\circ} \mathrm{C}$ for $1 \mathrm{~h}$ and stored in the desiccator for $24 \mathrm{~h}$ then the paper was weighed for final weights. The test was done with three repetitions (triplo). 


\section{Observation Parameters \\ Bug Mortality}

The mortality observation was performed by counting the number of bedbugs that died every day for 4 days, the accumulated amount calculated on the $4^{\text {th }}$ day. Percentage mortality of bedbug per glass of test was calculated using the following formula: $\%$ Mortality $=$ (Number of Bedbugs Dead) / (Number of Bedbugs Early) x 100\%.

\section{Percentage Weight Bait Paper Feed}

The percentage weight loss (PB) of feed paper after 4 days was calculated using the following formula:

$\% \mathrm{~Pb}=(\mathrm{B} 1-\mathrm{B} 2) / \mathrm{B} 1 \times 100 \%$

Description:

$\mathrm{B} 1=$ dry paper weight prior to feed $(\mathrm{g})$

B2 = dry weight of filter paper after feed (g)

\section{RESULTS AND DISCUSSION}

\section{Sweet Orange Peel Extract}

The sampling of orange peel extract was done by steam distillation method made from sweet orange peel. The isolation was carried out for $8 \mathrm{~h}$ and the result was $24 \mathrm{ml}$ of sweet orange peel extract of $2.6 \mathrm{~kg}$ orange peel. The essential oils produced was clear and contain a wide variety of terpen groups, sesquiterpenes, aldehydes, esters and sterols. Then the essential oil was stored in a bottle and in $-15^{\circ} \mathrm{C}$. The result of extract was taken $1 \mathrm{ml}$ for its d-Limonene concentration using GC-MS in Engineering Faculty Universitas Negeri Semarang. Here is the table of compounds from sweet orange peel extract.

Table 1: Compunds from sweet orange peel extract

\begin{tabular}{lc}
\hline Compound & $\begin{array}{c}\text { Content } \\
(\%)\end{array}$ \\
\hline D-limonena & 90,018 \\
1,6-Octadien-3-ol, 3,7-dimethyl- & 3,017 \\
$\beta$-Myrcene & 2,071 \\
3-Cyclohexene-1-methanol, $\alpha, \alpha, 4-$-trimethyl-, (S)- & 1,453 \\
Bicyclo[3.1.1]heptane, 6,6-dimethyl-2-methylene-, (1S)-- & 1,147 \\
6-Octen-1-ol, 3,7-dimethyl- & 0,667 \\
1R- $\alpha$-Pinene & 0,688 \\
1-Octanol & 0,589 \\
Octanal & 0,349 \\
\hline
\end{tabular}

The orange peel extract contains (dominant) $90.01 \%$ d-Limonene $\left(\mathrm{C}_{10} \mathrm{H}_{16}\right)$, so the d-Limonene was very dominant in the sweet orange peel. The results of other studies of citrus peel oil in Iran had been identified d-Limonene (92.42\%) and $\beta$-myrcene $(3.89 \%){ }^{5}$
Test Result of Bioassay Y d-Limonene Compound

The bioassay $Y$ test of the d-Limonene compound aims to recognize the interest of the insect on the $d$-Limonene compound. On the $Y$ rods a n-hexane solution as a control and a d-Limonene compound. It was placed in the same condition on the basis of $Y$ and other $Y$ branches. Then a bedbug was placed inserted. Once inserted and measured the time and distance traveled by foul decay, the result was in less than five minutes the bedbug dies and the distance traveled by $\pm 3-5 \mathrm{~cm}$. This test was done three times and had the same result. This means that bedbugs were not interested in d-Limonene compounds, and the d-Limonene compound was very powerful to turn off the bedbugs. The test was supported by 9 which revealed that the potential of volatile oils on insects was also resistant (repellent), fumigant, and antifeedant.

\section{SEM Test (Scanning Electron Microscopy) Nanoparticles d-Limonene with Chitosan}

Nanoparticles chitosan with d-Limonene were tested by SEM (Scanning Electron Microscopy) analysis conducted at the Physics Laboratory of the Faculty of Mathematics and Natural Sciences Universitas Negeri Semarang. SEM test aims to know the three-dimensional structure of a compound produced. Fig. 1, 2, 3, 4 and 5 show SEM test results with magnification 500, 1000, 5000 and 10000.

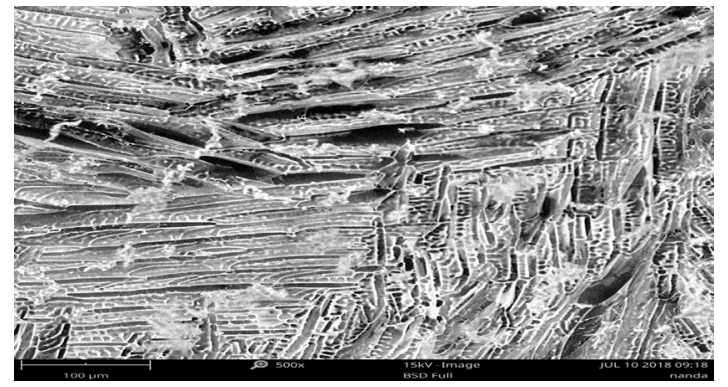

Fig. 2. Results of SEM Test with Magnification 500 times

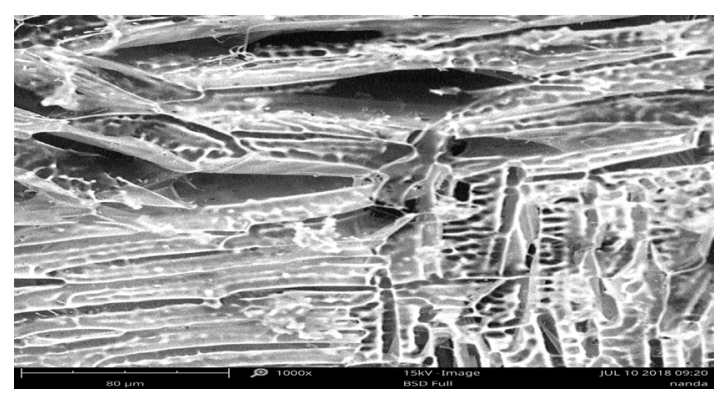

Fig. 3. Results of SEM Test with Magnification 1000 times 


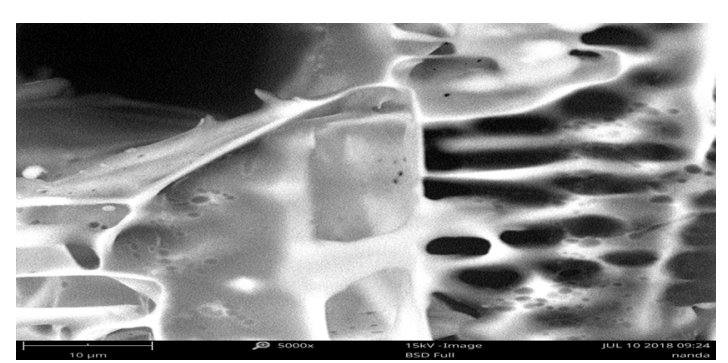

Fig. 4. SEM Test Results with Magnification 5000 times

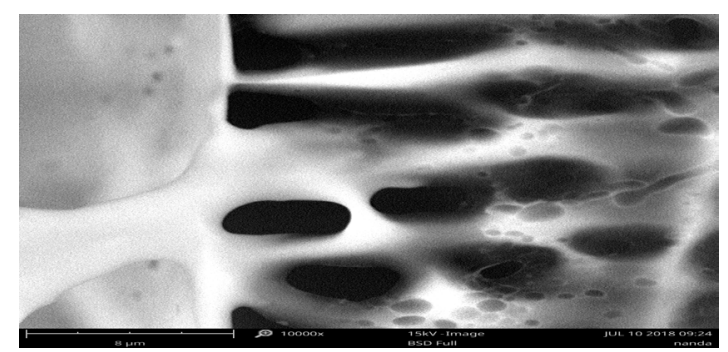

Fig. 5. SEM Test Results with Magnification 10000 times

From the test results obtained, surface morphology of $d$-Limonene nanoparticles showed irregular and rectangular surface conditions. This condition also illustrates that d-Limonene nanoparticles were not uniform and have uneven surfaces. ${ }^{13}$

\section{Anti Bugs Activity Test Results}

Anti-lice activity test using force feeding method. The principle of this forced feed was the diesel feed paper at $60^{\circ} \mathrm{C}$ for $1 \mathrm{~h}$ and stored in the desiccator for 24 hours. The feed paper was immersed in a solution of d-Limonene nanoparticles for $1 \mathrm{~h}$ then dried to evaporate the solvent. The $4 \mathrm{~cm}(4 \mathrm{~cm})$ diameter strimine cloth (modified) was placed in a test glass and on a strimin cloth was placed in the feed paper. Test glass was placed in a container with the bottom of which was given wet cotton. A total of 35 active bedbugs were inserted into the test glass. Test glass covered with black cloth and observed the activity of bedbugs. The results showed that d-Limonene nanoparticles were able to control bedbugs. The number of bedbugs that died for 4 days was 23 out of a total of 35 bedbugs with a concentration of $8 \%$ and 20 out of a total of 35 bedbugs with a concentration of $4 \%$.

Using of synthetic chemicals in pest control continuously caused directly detrimental to humans, wildlife, aquatic life, and the environment as a whole. Besides the negative effects of synthetic insecticides, most remote villages are unreliable and often forged or otherwise dissolved into ineffective, outdated concentrations due to their toxicity to humans and the environment, and ineffective due to the rapid evolution of pesticide resistance. ${ }^{14,15,16}$

However, this could be due to the necrosis or cytolysis of the hepatocytes by various toxic phytochemicals present in both Azadirachta indica and Citrus sinensis such as Azadirachtin and d-Limonene which probably cause leakage of the liver enzymes into the blood. This implies that these local insecticides cause hepatic injury which means that they have toxic effect on the liver of the experimental animals. This finding is consistent with the findings of Ashafa et al., (2012) who reported the toxic effects of Azadirachta indica and Tarkang et al., (2012) who reported the toxic effects of Citrus sinensis on the liver and other vital organs of experimental rats. ${ }^{17,18}$

\section{CONCLUSION}

Isolation of $2.6 \mathrm{~kg}$ of sweet orange peel produces $24 \mathrm{ml}$ of essential oil. Characterization of GC-MS essential oils of sweet orange peel containing the main component compounds were d-Limonene (90.018\%), 1,6-Octadien-3-ol, 3,7-dimethyl- (3,017\%), $\beta$-Myrcene $(2.071 \%)$, Octanal $(0.349 \%), 1-$ Octanol $(0.589 \%), 1 \mathrm{R}-\alpha-$ Pinene $(0.688 \%)$, 6-Octen-1-ol, 3,7-dimethyl- $(0.667 \%)$, 3-Cyclohexene-1- methanol, $\alpha, \alpha, 4$-trimethyl-, (S)-(1.453\%), and Bicyclo [3.1.1] heptane, 6.6-dimethyl-2-methylene-, (1S)- (1.147\%). Bioassay Y test between d-Limonene and $\mathrm{N}$-hexane compounds showed that $d$-Limonene is resistant (repellent) and fumigant (fumigant). Characterization of $d$-Limonene nanoparticles had an uneven and irregular surface morphology. Anti-flea activity test by using force-feed method indicates more than $50 \%$ dead blight and showed that orange peel extract (Citrus Sinensis L.) can be used as a natural insecticide for bed bug controller (Cimex Cimicidae).

\section{ACKNOWLEDGEMENT}

\section{Acknowledgments author to convey to:}

1) Directorate General of Learning and Student Affairs, Ministry of Research, Technology and Higher Education, Indonesia with contract number 1020/B3.1/KM/2018 dated March 09th, 2017 for research funding that had been given.

2) Supervisor of PKM-PE, Dr. Sri Mursiti, M.Si. and Supervisor PKM Universitas Negeri Semarang who had provided advice, input, motivation, and prayer.

3) Universitas Negeri Semarang as our institution to gain knowledge. 
4) Chemistry Laboratory FMIPA Universitas Negeri Semarang who had served the purposes of research.

5) Chemical Engineering Laboratory FT Universitas Negeri Semarang who had served the purposes of research.
6) Physics Laboratory FMIPA Universitas Negeri Semarang who had served the purposes of research.

\section{Conflicts of Interest}

The authors declare no conflict of interest.

\section{REFERENCES}

1. Ahmad I. Fakta tentang kutu busuk (bed bugs) Cimex hemipterus (Hemiptera: Cimicidae) dan cara pengendaliannya. Institut Teknologi Bandung., 2014.

2. Khan HR, Rahman MDM. Morphology and biology of the bedbug Cimex hemipterus (Hemiptera: Cimicidae) in the laboratory. Dhaka Uni J Biol Sci., 2012, 21(2), 125-130.

3. Tawatsin A, Thavara U, Chompoosri J, Phusup Y, Jonjang N, Khumsawads C, Bhakdeenuan P, SawanpanyalertP, Asavadachanukorn P, Mullas MIRS, Siriyasatien P, Insecticide resistance in bedbugs in Thailand and laboratory evaluation of insecticides for the control of Cimex hemipterus and Cimex lectularius (Hemiptera: Cimicidae). J Med Entomol., 2011, 48(5), 1023-1030.

4. Abdallah, M.S.I., Muhammad, I., Warodi, F. A. Review on Some Plants as Bio - Pesticides. International Journal of Contemporary Research and Review., 2017, 8(1), 20186-20191.

5. Hebeish, A., Fouda, M. M. G., Hamdy, I. A., El-sawy, S. M. and Abdel-mohdy, F. A. Preparation of durable insect repellent cotton fabric : Limonene as insecticide, Carbohydrate Polymers., 2008, 74(2), 268-273.

6. Fattah, A., Sh, M., Yehia, H. A., Fouzy, A. S. M., Ramadan, M. M. and Nooh, A. Antifungal efficacy and chemical composition of essential oil from the Egyptian sweet orange peel (Citrus sinensis, L). Manuscript Info Abstract., 2015, 3(10), 1257-1269.

7. Azar, P. A., Nekoei M., Larijani K., and Bahraminasab S. Chemical composition of the essential oils of citrus sinensis, valencia and a quantitative structure-retention relationship study for the prediction of retention indices by multiple linear regression, J. Serb. Chem. Soc., 2011, 76(1), 1627-1637.

8. Tiilikkala, K., Holopainen, J. K. and Campus, K. 'Insecticidal, repellent, antimicrobial activity and phytotoxicity of essential oils : With special reference to limonene and its suitability for control of insect pests', (December)., 2008. doi: 10.23986/afsci.5697.

9. Koul, O., S. Walia, and G. S. Dhaliwal., Essential oils as green pesticides: Potential and constrains, J. Biopestic. Int., 2008, 4(1), 63-84.
10. Erasto, P. and Viljoen, A. 'Limonene - A review : Biosynthetic , ecological and pharmacological relevance This Issue is Dedicated to Professor Gerhard Buchbauer on the Occasion of his 65 th Birthday', (January)., 2016.

11. Wudil, A. M., Muhammad, M. G. and Al-khatib, A. J. 'Toxicological Effect Of Local/Natural Insecticides: Seeds Of Azadirachta Indica, Peels Of Citrus Sinensis And Their Combination On Liver Enzymes., 2014, 10(21), 324-333.

12. Kartini, E., Jayuska, A., dan Alimuddin, A.H., Uji Aktivitas Biotermitisida Minyak Atsiri Daun Citrus nobilis Lour Terhadap Rayap Tanah (Coptotermes curvignathus $\mathrm{sp}$ ), J. Kimia Khatulistiwa., 2013, 3(1), 1-6.

13. Mannuela, Novella. Preparasi dan Evaluasi Nanopartikel Azitromisin-Kitosan dan UjiAktivitas Antibakteri terhadap Bakteri Propionibacterium acnes. Pontianak : Universitas Tanjungpura., 2016.

14. Rauh, V., Arunajadadai, S., Horton, M., Perera, F., Hoepner, L., Barr, D.B., Whatt, R., Seven year neuro development scores and prenatal exposure to chlorpyrifos, a common agricultural pesticide. Environmental Health Perspectives., 2011, 119, 1196-1201.

15. Muñoz-Quezada, M.T., Lucero, B.A., Barr, D.B., Steenland, K., Levy, K., Ryan, P.B., Iglesias, V., Alvarado, S., Concha, C., Rojas, E., Vega, C., Neurodevelopmental effects in children associated with exposure to organophosphate pesticides: a systematic review. Neurotoxicology., 2013, 39, 158-168.

16. Shaia, P., and Mills, P.K. Cancer incidence in California farm workers, 1988- 2010. American Journal of Industrial Medicine., 2014, 57, 737-747.

17. Ashafa, A. O. T., Orekoya, L. O., Yakubu, M. T. Toxicity profile of ethanolic extract of Azadirachta indica stem bark in male Wistar rats. Asian Pacific Journal of Tropical Biomedicine., 2012, 2(10), 811-817.

18. Tarkang, P. A., Agbor, G. A., Armelle, T. D., Tchokouaha, L. R. Y., Kemeta, D., Ngadena, Y. S. M. Acute and sub-chronic toxicity studies of the aqueous and ethanolleaf extracts of Citrus sinensis (Linnaeus) Osbeck (pro sp.) in Wistar rats. Der Pharmacia Lettre., 2012, 4(5), 1619-1629. 